\title{
Semmes Weinstein Monofilament Examination
}

National Cancer Institute

\section{Source}

National Cancer Institute. Semmes Weinstein Monofilament Examination. NCI

Thesaurus. Code C129294.

A noninvasive screening tool for peripheral neuropathy. A monofilament strand is pressed on a test site perpendicularly until it bends. If a patient fails to sense the monofilament after it bends, the test site is considered to be insensate. 